Open Access

\title{
Blastocystis specific serum immunoglobulin in patients with irritable bowel syndrome (IBS) versus healthy controls
}

Robyn Nagel ${ }^{1,5^{*}}$, Rebecca J. Traub ${ }^{1,2}$, Marcella M S Kwan ${ }^{3}$ and Helle Bielefeldt-Ohmann ${ }^{1,4}$

\begin{abstract}
Background: Blastocystis species are common enteric human parasites and carriage has been linked to Irritable Bowel Syndrome (IBS), particularly diarrhoea-predominant IBS. The spectrum of immune reactivity to Blastocystis proteins has been reported previously in symptomatic patients. We investigated differences in serum immunoglobulin profiles between patients with IBS, both positive and negative for Blastocystis carriage, and healthy controls (HC).
\end{abstract}

Methods: Forty diarrhoea-predominant IBS patients (26 patients positive for Blastocystis sp., 14 negative patients) and forty HC (24 positive, 16 Blastocystis-negative) were enrolled. Age, gender, ethnicity and serum immunoglobulin A (IgA) levels were recorded and faecal specimens were analysed using smear, culture and polymerase chain reaction amplification of ribosomal DNA. Sera were tested in Western blots and the reactivities compared to known targets using monoclonal antibodies Blastofluor ${ }^{\circledast}$ (Blastocystis specific antibody), MAb1D5 (cytopathicto Blastocystis cells), anti-promatrix metalloprotease-9 (anti-MMP-9) and SDS-PAGE zymograms.

Results: Levels of serum IgA were significantly lower in Blastocystis carriers $(p<0.001)$ but had no relationship to symptoms. Western blots demonstrated serum IgG antibodies specific for Blastocystis proteins of 17,27,37,50,60-65, 75-90, 95-105 and $150 \mathrm{kDa}$ MW. Reactivity to the 27, 50 and 75-95 kDa proteins were found more frequently in the IBS group compared to the HC's $(p<0.001)$ and correlation was greater for Blastocystis-positive IBS patients $(p<0.001)$ than for negative IBS patients $(p<0.05)$. MAb1D5 reacted with proteins of 27 and $100 \mathrm{kDa}$, and anti-MMP-9 with 27, 50 and 75-100 kDa proteins. Bands were seen in zymograms around $100 \mathrm{kDa}$.

Conclusions: Low serum IgA levels are associated with Blastocystis carriage. All IBS patients were more likely to demonstrate reactivity with Blastocystis proteins of $27 \mathrm{kDa}$ (likely a cysteine protease), 50 and 75-95 kDa MW compared to HC. The presence of antibodies to these Blastocystis proteins in some Blastocystis-negative subjects suggests either prior exposure to Blastocystis organisms or antibody cross reactivities. The anti-proMMP-9 reaction at 50 and $75-100 \mathrm{kDa}$ and the zymogram result suggest that metalloproteases may be important Blastocystis antigens.

Trial registration: Australian and New Zealand Clinical Trials registry ACTRN: 12611000918921

Keywords: Blastocystis, Irritable bowel syndrome, Immunoglobulin A, Western blotting, proteases

\footnotetext{
* Correspondence: robynnagel@tgclinic.com.au

${ }^{1}$ School of Veterinary Science, The University of Queensland, Gatton Campus,

Gatton, QLD 4343, Australia

${ }^{5}$ Toowoomba Gastroenterology Clinic, Suite 105 Medici Medical Centre, 15

Scott St, Toowoomba, QLD 4350, Australia

Full list of author information is available at the end of the article
}

(C) 2015 Nagel et al. Open Access This article is distributed under the terms of the Creative Commons Attribution 4.0 International License (http://creativecommons.org/licenses/by/4.0/), which permits unrestricted use, distribution, and reproduction in any medium, provided you give appropriate credit to the original author(s) and the source, provide a link to the Creative Commons license, and indicate if changes were made. The Creative Commons Public Domain Dedication waiver (http://creativecommons.org/publicdomain/zero/1.0/) applies to the data made available in this article, unless otherwise stated. 


\section{Background}

Irritable bowel syndrome (IBS) is a common clinical condition affecting up to $10 \%$ of the global population and characterised by abdominal pain, bloating and disturbance of bowel habit [1]. The underlying cause of IBS is not known although differences in gut motility, the enteric immune and nervous system, intestinal permeability, systemic cytokine production, faecal protease excretion, faecal microflora and psychological profiles have been reported in this condition [2]. The disease is defined by a clinical symptom complex description (Rome III) [3] that has a sensitivity of $70 \%$ and a specificity of $80 \%$ in differentiating IBS patients from patients with other gastrointestinal diseases [4]. This clinical definition is the gold standard, but assessment can be subjective. Reliable, clinically applicable IBS biomarkers, particularly if they direct therapeutic choices, would be useful. Serum biomarkers for IBS have been investigated in two previous studies $[5,6]$ and both were less accurate than using the Rome III criteria. Post-infectious IBS is known to comprise $10 \%$ of the total cases of IBS and this has stimulated interest in the faecal microbiota as a possible contributing cause of IBS [7]. The carriage of the enteric organism Blastocystis has been reported to be three times higher in patients with diarrhoea predominant IBS (D-IBS) compared to healthy controls [8], making it an organism of interest in IBS.

Blastocystis sp. are the most common parasites found in human stool [9]. Sub-typing of the18S ribosomal DNA(rDNA) has identified 17 different subtypes (ST's) and nine have been identified in humans $[10,11]$. Carriage of Blastocystis sp. is increased in patients with various types of immunosuppression [9] and in patients with irritable bowel syndrome [8]. Nevertheless, many carriers are healthy and a definite association between carriage and illness has not been proven in epidemiological studies [12].

Blastocystis sp. reside in the intestinal lumen, establishing in the ileum and caecum adherent to the outer layer of mucus $[13,14]$, with only rare reports of mucosal invasion. Antibodies specific for Blastocystis antigens have been demonstrated in the faeces and the serum of carriers [15-19] and antibody titres have been reported to be higher with length and severity of infection [15]. These antibodies have been described in all immunoglobulin classes. IgA antibodies specific forBlastocystis sp. have been shown to be present in pig faeces [19] and in both faeces and serum of infected humans [20]. Our previous pilot study demonstrated lower serum IgA levels in IBS patients positive for Blastocystis carriage than in other patient groups or healthy controls [21].

Blastocystis specific immunoglobulin G (IgG) antibodies have also been detected in serum [15, 20,22] and faeces of Blastocystis infected humans [20], with lower titres in the latter compartment. Using SDS-PAGE and Western blot analysis, serum IgG has been reported to react with Blastocystis-specific proteins of $12 \mathrm{kDa}$ [16], $29 \mathrm{kDa}, 50 \mathrm{kDa}$ and $118 \mathrm{kDa}$ molecular weights (MWs) [17]. Antibody reactivity to a $29 \mathrm{kDa} \mathrm{MW}$ Blastocystis protein has been reported to be more common in the serum of symptomatic patients compared to asymptomatic individuals [18], and subsequent protein sequencing of a $30 \mathrm{kDa}$ protein showed it to possess $50 \%$ homology with known cysteine protease (legumain type) peptide sequences [23]. A monoclonal IgM antibody 1D5 (MAb1D5), known to be cytopathic to Blastocystis organisms [24] as well as a human legumain antibody both bind to this $30 \mathrm{kDa}$ Blastocystis antigen in Western blots.

Protease secretion is a recognised virulence mechanism for parasites [25] facilitating tissue/cell invasion, protein activation and immunoevasion. These molecules are also highly immunogenic. Analysis of the genome of Blastocystis ST7 has led to the predictions that the parasite would be able to produce all major classes of proteases, including serine proteases, metalloproteases and perhaps as many as 20 different cysteine proteases [26, 27]. Notably Blastocystis proteases have been shown to cleave human secretory IgA [28] and induce production of the pro-inflammatory cytokine interleukin-8 (IL-8) by enterocytes in an in vitro model system [29].

Our aim was to explore the clinical relevance of Blastocystis sp. in patients with diarrhoea predominant IBS by assessing serum antibody reactivities specific for Blastocystis. In this study we compared the serum IgA levels in IBS patients, either positive (IBS-P) or negative (IBS-N) for Blastocystis carriage, and healthy controls (positive (HC-P) and negative (HC-N) for Blastocystis). IgG serological responses to specific Blastocystis antigens were examined in all these subgroups using Western blotting techniques. Identification of specific Blastocystis antigens was attempted by probing the Western blots with Blastocystis specific antibody (Blastofluor ${ }^{\bullet}$, Antibodies Inc), MAb1D5 and pro-matrix metalloprotease 9 (anti-MMP-9) antibody.

\section{Methods}

\section{Study outline}

Forty patients presenting with diarrhoea-predominant IBS to the Toowoomba Gastroenterology Clinic and forty healthy volunteers were enrolled in the study and signed written consent forms. The study was approved by the University of Queensland Medical Research Ethics Committee and was part of a clinical trial that is registered with the Australian and New Zealand Clinical Trials registry (http://www.ANZCTR.org.au) ACTRN: 12611000918921. Single baseline faecal and serum 
samples were collected from all participants. Total serum IgA levels were measured in all participants and faecal and serum specimens underwent further microbiological, molecular and Western blot analysis.

\section{Ethical approval}

The study was approved by the University of Queensland Medical Research Ethics Committee (No 2011000454).

\section{Inclusion protocol}

Adult patients presenting with chronic diarrhoea and abdominal pain from $1 / 8 / 11$ to $20 / 02 / 14$ were assessed clinically. Baseline blood tests, including full blood count, serum calcium, thyroid function tests, serum IgA and coeliac antibody tests were performed. Other pathogens known to cause chronic diarrhoea such as Salmonella sp, Shigella sp, Vibriosp., Campylobacter sp, Aeromonas sp),Giardia duodenalis, Clostridium difficule and Dientamoebahistolytica were excluded with faecal microscopy, culture and PCR testing performed by a commercial pathology laboratory. All patients proceeded to an upper and lower endoscopy that included gastric antral, duodenal, ileal and colonic biopsies. Forty eligible symptomatic patients who had no other cause for symptoms and who fulfilled the Rome criteria [30] for diarrhoea predominant IBS were enrolled in the study. Of these, 26 patients were positive for Blastocystis (IBS-P) and 14 were negative (IBS-N). Forty healthy volunteers working at the University of Queensland and with no gastrointestinal symptoms in the preceding 12 months were tested for Blastocystis sp. infection, 24 were positive (HC-P) and 16 were negative (HC-N). Details of age, gender and ethnicity of participants were recorded.

\section{Exclusion protocol}

Only non-pregnant adults between 18 and 75 years of age were recruited for the study. Patients with significant systemic diseases or co-morbidities were excluded.

\section{Diagnosis of Blastocytis infection}

All samples were run in parallel for the presence of Blastocystis sp. using a simple unstained wet faecal smear, xenic in vitro culture (XIVC) and PCR (confirmed as Blastocystis sp. using DNA sequencing). A study participant was considered to be positive if any one of the tests was positive as described previously [21].

\section{Serum Immunoglobulin A}

Serum samples were stored at $-20{ }^{\circ} \mathrm{C}$ prior to analysis at Sullivan and Nicolaides Pathology Service, Brisbane, Queensland using a Siemens BNII Nephelometer (Siemens, Munich, Germany) and Siemens reagents.

\section{Western blotting}

\section{Antigen preparation}

An axenic strain of Blastocystis sp. ST4 (WR1) was cultured anaerobically in pre-reduced Iscove's Modified Dulbecco's medium (IMDM) (Sigma-Aldrich, St Louis, USA: 13390) enriched with $10 \%$ heat-inactivated horse serum (Gibco: 26050088). WR1 was originally obtained from the stool of Wistar rats in Singapore but has been in continuous axenic culture for more than seventeen years. Blastocystis antigen was prepared using the proteinase inhibitor Complete Lysis-B (2x), EDTA-free kit (Roche, Mannheim, Germany:04719948001) and stored at $-20{ }^{\circ} \mathrm{C}$ until required.

\section{SDS-PAGE protocol}

Approximately $300 \mathrm{ng}$ of Blastocystis antigen was mixed with equal volumes of loading buffer (Laemmli sample buffer mixed with $2 \mathrm{M}$ 2-mercaptoethanol in a ratio of 19:1vol:vol (Bio- Rad, California, USA)) and loaded into the large well of a preparative 4-15\% Tris- $\mathrm{HCl}$ Ready Gel (Bio-Rad: 161-1140). A separate single protein standard ladder well in the gel was loaded with $15 \mathrm{uL}$ of Precision Plus Protein Western C Standard (Bio-Rad: 161-0385). The gel was electrophoresed in M Tris/ Glycine/SDS buffer (Bio-Rad: 161-0732) at $100 \mathrm{~V}$ for 40-60 min at room temperature and then rinsed three times with deionised water. The proteins were transferred to a nitrocellulose membrane using $1 \mathrm{M}$ Tris/Glycine/20 \% methanol buffer electrophoresed at $100 \mathrm{~V}$ for $60 \mathrm{~min}$ at $4{ }^{\circ} \mathrm{C}$. The membrane was rinsed three times with $0.1 \% 1 \mathrm{Mphosphate}$ buffered saline (PBS)/Tween 20 (PBST) (Sigma Aldrich, St Louis, USA: P5927) solution and then blocked in $100 \mathrm{ml}$ of blocking solution ( $0.1 \%$ PBST, 4 g skim milk and1g bovine serum albumin per $100 \mathrm{ml}$ (Sigma Aldrich: A2153) for $60 \mathrm{~min}$ at room temperature. The membrane was cut into strips and stored at $-20{ }^{\circ} \mathrm{C}$ till required.

\section{Immunolabeling protocol}

Membrane strips were incubated with primary antibody (patient sera or MAbs) diluted in $1 \mathrm{~mL}$ of Signal Boost $^{\mathrm{TM}}$ Immunoreaction Enhancer Kit (Calbiochem, Darstadt, Germany: 407207) Solution One for 24 h on a rocker platform at $4{ }^{\circ} \mathrm{C}$ before washing consecutively three times for $15 \mathrm{~min}$ in PBST. The strips were then incubated with secondary antibody diluted in Signal Boost Solution Two at room temperature for $1 \mathrm{~h}$ on a rocker platform and the washing steps repeated.

The patient sera were diluted 1:10 and the secondary antibody was a 1: 2000 dilution of horseradish peroxidase (HRP)-conjugated goat anti-human IgG Ab (Sigma Aldrich:A8786).

An additional four antibodies were tested for reactivity with the Blastocystis antigens:(i) a mouse derived 
Blastocystis-cytopathic monoclonal IgM antibody, MAb1D5 (purified Mab against surface legumain of Blastocystis ST7, IgM, $16 \mu \mathrm{g} / \mu \mathrm{L}$ ) [27, 31, 32], (ii) a control unrelated mouse derived monoclonal IgM antibody, MAb5, (iii) a rabbit polyclonal anti-Blastocystis ST3 antibody (Blastofluor $^{\odot}$ ) [33], and (iv) a rabbit polyclonal anti-human matrix metalloproteinase 9 (Anti-MMP-9) (Calbiochem: 444236). These primary antibodies were diluted 1:100, and the secondary antibodies1:1000, using HRP-conjugated-goat antimouse IgM (Sigma, St Louis, USA: Cat no: A8786) and HRP-conjugated anti-rabbit polyclonal Ab, respectively.

All blots were run with a protein standard ladder and a negative control. Negative controls were prepared according to the protocol above except exclusion of serum/primary antibody in step one followed by incubation with the secondary antibody.

The antibody binding was visualized using Clarity Western ECL Substrate (Bio Rad, California USA) and a Bio Rad Chemi-Doc ${ }^{\mathrm{TM}}$ XRS Gel Documentation system. The brightness and contrast was adjusted over entire images to optimise the image but no differential image manipulation was used on separate lanes.

\section{Zymograms}

The Blastocystis antigen was prepared as per the Western blotting protocol and combined with Zymogen buffer (Bio-Rad: 161-0764) in a vol:vol ratio of 1:1. Approximately $50 \mathrm{ng}$ of buffered Blastocystis antigen was loaded into each well of a $10 \%$ gelatin Ready $\mathrm{Gel}^{\circ}$ Zymogram Gel (Bio-Rad: 161-1167) and the gel was electrophoresed in $1 \mathrm{M}$ Tris/Glycine/SDS buffer (Bio-Rad: 161-0732) at $90 \mathrm{~V}$ for 40-60 $\mathrm{min}$ at room temperature. The gel was cut in half and both gels subjected to renaturation and development steps. The gels were incubated in $100 \mathrm{~mL}$ of Zymogen Renaturation buffer (Bio-Rad: 161-0765) for $1 \mathrm{~h}$ at room temperature on a rocker platform and then incubated in $100 \mathrm{~mL}$ of Zymogen Development buffer (Bio-Rad: 161-0766) for $24 \mathrm{~h}$ at $37{ }^{\circ} \mathrm{C}$ without or with protease inhibitor, $1 \mathrm{mM}$ EDTA (ethylenediaminetetraacetic acid), added to the two solutions for one gel. The buffer was decanted and the gels were stained with $100 \mathrm{~mL}$ Aqua $^{\oplus}$ stain (Bulldog Bio, Portsmouth, UK) for 15 min on a rocker platform and rinsed with deionised water.

\section{Statistical analysis}

Statistical analysis was carried out using SPSS v.22 [34]. The level of IgA was transformed using natural logarithm to get a normal distribution. A one-way Analysis of Covariance (ANCOVA) was used to compare the level of IgA between the four groups, adjusting for potential confounders, such as seasonality [35]. Pearson's chi-square/ Fisher exact test were used to assess the significance of association between subjects with IBS and healthy controls with the presence of serum IgG antibodies detected against Blastocystis proteins of various sizes.

\section{Results}

\section{Study subjects}

The eighty study participants comprised forty symptomatic IBS patients (26 positive and 14 negative for Blastocystis carriage) and forty asymptomatic healthy controls (24 positive and 16 negative for Blastocystis). The average participants' age was $45.2 \pm 14.4$ years (range 16-75 years). There were no significant between-group differences in terms of age $(\mathrm{F}(3,76)=0.81, p=0.49)$ and gender distribution $\left(\lambda^{2}=4.37, p=0.22\right)$. However, there were significantly more Caucasians compared to non-Caucasians in the IBSP, IBS-N and HC-P groups $\left(\lambda^{2}=16.83, p=0.001\right)$. The Blastocystis sp. subtypes detected were ST3 (34\%), ST4 (26\%), ST1 (16\%), ST2 and ST7 (8\%), ST8 (6\%) and ST5 (2\%). Characteristics of the 80 subjects and their Blastocystis subtypes are given in Tables 1 and 2 .

\section{Serum IgA levels}

Serum IgA levels were higher in male $(2.36 \pm 1.36 \mathrm{~g} / \mathrm{L})$ compared to female participants $(1.79 \pm 1.09 \mathrm{~g} / \mathrm{L})(\mathrm{t}=4.15$,

Table 1 Demographic and epidemiological characteristic of subgroups

\begin{tabular}{lllll}
\hline & $\begin{array}{l}\text { IBS-P } \\
(n=26)\end{array}$ & $\begin{array}{l}\text { IBS-N } \\
(n=14)\end{array}$ & $\begin{array}{l}\text { HC-P } \\
(n=24)\end{array}$ & $\begin{array}{l}\text { HC-N } \\
(n=16)\end{array}$ \\
\hline Age (years; mean \pm SD) & $44.5 \pm 15.2$ & $44.5 \pm 14.2$ & $48.7 \pm 13.2$ & $41.7 \pm 15.0$ \\
Female $(n, \%)$ & 19 & 11 & 12 & 11 \\
Caucasian $(n, \%)$ & $26(100)$ & $13(93)$ & $21(88)$ & $9(56)$ \\
Season recruited $(n)$ & & & & \\
Spring & 2 & 3 & 19 & 0 \\
Summer & 8 & 5 & 4 & 1 \\
Autumn & 11 & 4 & 0 & 7 \\
Winter & 5 & 2 & 1 & 8
\end{tabular}

Blastocystis subtype distribution

\begin{tabular}{|c|c|c|}
\hline ST1 & 2 & 6 \\
\hline ST2 & 1 & 3 \\
\hline ST3 & 9 & 8 \\
\hline ST4 & 9 & 4 \\
\hline ST5 & 0 & 1 \\
\hline ST6 & 0 & 0 \\
\hline ST7 & 3 & 1 \\
\hline ST8 & 2 & 1 \\
\hline Serum $\lg A^{a}$ & $1.63 \pm 0.95 \quad 2.19 \pm 1.01$ & $1.54 \pm 0.76$ \\
\hline
\end{tabular}

$(\mathrm{g} / \mathrm{L} ;$ mean $\pm \mathrm{SD})$

$S D$ : standard deviation

IBS-P/N: Irritable bowel syndrome subjects positive/negative for Blastocystis $H C-P / N$ : Healthy control subjects positive/negative for Blastocystis

ST: subtype; $\lg A$ : Immunoglobulin A

${ }^{a}$ unadjusted mean; results IgA of different subtypes in IBS-P \& HC-P groups were pooled for analysis purpose 
Table 2 Serum antibody reactions to Blastocystis antigens detected by Western immunoblotting in all subjects infected with different subtypes of Blastocystis

\begin{tabular}{|l|l|l|l|l|l|l|l|}
\hline \multirow{2}{*}{$\begin{array}{c}\text { Protein band at } \\
\text { molecular weight }\end{array}$} & \multicolumn{6}{|c|}{ Number of subjects infected with particular subtype of Blastocystis } \\
\cline { 2 - 8 } & $\mathbf{S T 1}$ & $\mathbf{S T 2}$ & $\mathbf{S T 3}$ & $\mathbf{S T 4}$ & $\mathbf{S T 5}$ & $\mathbf{S T 7}$ & ST8 \\
\cline { 2 - 8 } & $\mathbf{( n = 8 )}$ & $\mathbf{( n = 4 )}$ & $\mathbf{( n = 1 7 )}$ & $\mathbf{( n = 1 3 )}$ & $\mathbf{( n = 1 )}$ & $\mathbf{( n = 4 )}$ & $\mathbf{( n = 3 )}$ \\
\hline $\mathbf{1 7} \mathbf{k D a}$ & 2 & & 3 & 1 & & & \\
\hline $\mathbf{2 7} \mathbf{~ k D a}$ & 7 & 3 & 16 & 10 & 1 & 2 & 3 \\
\hline $\mathbf{3 7} \mathbf{~ k D a}$ & 1 & 2 & 2 & 1 & & & \\
\hline $\mathbf{5 0} \mathbf{~ k D a}$ & 7 & 2 & 14 & 11 & 1 & 4 & 3 \\
\hline $\mathbf{6 0 - 6 5} \mathbf{~ k D a}$ & 7 & 4 & 16 & 11 & 1 & 3 & 3 \\
\hline $\mathbf{7 5 - 9 0} \mathbf{~ k D a}$ & 8 & 4 & 12 & 9 & 1 & 3 & 2 \\
\hline $\mathbf{9 5 - 1 0 5} \mathbf{~ k D a}$ & 5 & 1 & 10 & 7 & 1 & 2 & 2 \\
\hline $\mathbf{1 5 0} \mathbf{~ k D a}$ & 5 & 3 & 8 & 2 & 1 & 2 & \\
\hline
\end{tabular}

Absence of bands

ST: subtype $\quad k D a:$ kiloDalton

$p<0.05)$. Levels of IgA were not found to be different between Caucasian and Asian participants, nor across the different Blastocystis subtypes (both $p>0.05$ ).

The average level of serum IgA was lowest in the HC-P group, followed by IBS-P, IBS-N and HC-N (Table 1). Participants who tested Blastocystis-positive (combined IBS-P and HC-P subgroups) had a significantly lower serum IgA level $(1.59 \pm 0.54 \mathrm{~g} / \mathrm{L})$ than their Blastocystis- negative counterpart (combined IBS-N and HC-N) subgroups $(2.65 \pm 1.41 \mathrm{~g} / \mathrm{L}) \quad(\mathrm{t}(78)=4.06, p<0.001)$. Planned contrasts revealed that participants in the HC-N group had significantly higher serum IgA levels compared to those in the IBS-P group, $\mathrm{t}(75)=-3.31, p=0.001$, and HC-P group, $\mathrm{t}(75)=-4.30, p<0.001$. Pairwise comparisons showed that IgA levels in IBS-N participants were higher than those in the HC-P group $(p<0.01)$.

There was a significant difference in IgA levels between the four groups after controlling for the potential confounding effect of seasonality and gender, $\mathrm{F}(3,73)=$ $9.05, p<0.001$. The gender covariate was significantly related to the level of $\operatorname{IgA},(\mathrm{F}(1,73)=7.93, p<0.01)$, whereas seasonality, was not $(\mathrm{F}(1,75)=3.42, p=0.07)$.

\section{Blastocystis-specific serum IgG antibody bands}

Western blots were employed to assess the serum IgG response to Blastocystis proteins in the four clinical groups and the analysis of these results is shown in Tables 2, 3 and 4. Reactivity was seen to Blastocystis proteins of approximately 27, 50, 60-65, 75-90, 95-105 and 150kDaMW [36] in all groups of patients (Figs. 1, 2, 3). These results were examined to assess whether serum reactivity to Blastocystis proteins of different sizes was associated with carriage of a particular subtype of Blastocystis sp., or either the presence of Blastocystis sp. orIBS symptoms. If Blastocystis sp. were to prove to be a cause of IBS then it is possible that IBS$\mathrm{N}$ patients may have had Blastocystis infection in the relatively recent past and the subgroups with IBS were analysed separately in order to reduce any contribution from pre-existing antibodies (Table 4).

The numbers of Blastocystis-positive subjects in each subtype group were small but serum reactivity to all the protein bands was present in every subtype with the exception of $17 \mathrm{kDa}, 37 \mathrm{kDa}$ and $150 \mathrm{kDa}$ bands (Table 2). No significant associations were found between Blastocystis sp. subtypes and reactivity to particular protein bands based on Fisher's exact test results (all $p>0.05$ ).

Table 3 Serum antibody reactions to Blastocystis antigens detected by Western immunoblotting in different clinical groups

Protein band Number of subjects with presence of protein bands $(n, \%)$ at molecular $\mathrm{IBS}-\mathrm{P}(n=26) \quad$ IBS-N $(n=14) \quad \mathrm{HC}-\mathrm{P}(n=24) \quad$ HC-N $(n=16)$ weight

\begin{tabular}{lllll}
\hline $17 \mathrm{kDa}$ & $1(4)$ & $0(0)$ & $5(21)$ & $0(0)$ \\
$27 \mathrm{kDa}$ & $25(96)$ & $12(86)$ & $17(71)$ & $7(44)$ \\
$37 \mathrm{kDa}$ & $3(12)$ & $0(0)$ & $3(13)$ & $0(0)$ \\
$50 \mathrm{kDa}$ & $26(100)$ & $13(93)$ & $16(67)$ & $8(50)$ \\
$60-65 \mathrm{kDa}$ & $26(100)$ & $12(86)$ & $19(80)$ & $13(81)$ \\
$75-90 \mathrm{kDa}$ & $25(96)$ & $13(93)$ & $14(58)$ & $9(56)$ \\
$95-105 \mathrm{kDa}$ & $14(54)$ & $3(21)$ & $14(58)$ & $2(13)$ \\
$150 \mathrm{kDa}$ & $5(19)$ & $1(7)$ & $16(67)$ & $1(6)$ \\
\hline
\end{tabular}
IBS-P/N: Irritable bowel syndrome subjects positive/negative for Blastocystis HC-P/N: Healthy control subjects positive/negative for Blastocystis $n$ : number kDa: kiloDalton 
Table 4 Comparison of presence of Blastocystis and/or gastrointestinal symptoms to specific sized antibody bands directed against Blastocystis proteins using Western immunoblotting

\begin{tabular}{|c|c|c|c|c|c|c|c|c|c|c|c|c|c|c|c|c|c|}
\hline \multirow{3}{*}{ Gp1 } & \multirow{3}{*}{ Gp2 } & \multicolumn{16}{|c|}{ Presence of antibody to Blastocystis protein at band MW (n, \%) } \\
\hline & & \multicolumn{2}{|c|}{$17 \mathrm{kDa}$} & \multicolumn{2}{|c|}{$27 \mathrm{kDa}$} & \multicolumn{2}{|c|}{$37 \mathrm{kDa}$} & \multicolumn{2}{|l|}{$50 \mathrm{kDa}$} & \multicolumn{2}{|c|}{ 60-65 kDa } & \multicolumn{2}{|c|}{ 75-90 kDa } & \multicolumn{2}{|c|}{ 95-105 kDa } & \multicolumn{2}{|l|}{$150 \mathrm{kDa}$} \\
\hline & & $\overline{\mathrm{Gp} 1}$ & Gp2 & Gp1 & Gp2 & Gp1 & Gp2 & Gp1 & Gp2 & Gp1 & Gp2 & Gp1 & Gp2 & Gp1 & Gp2 & Gp1 & Gp2 \\
\hline \multicolumn{18}{|l|}{ Blastocystis presence } \\
\hline IBS-P \& HC-P $(n=50)$ & IBS-N \& HC-N $(n=30)$ & $6(12)$ & $0(0)^{*}$ & $42(84)$ & $19(63)^{*}$ & $6(12)$ & $0(0)^{*}$ & $42(84)$ & $21(70)$ & $45(90)$ & $25(83)$ & $39(78)$ & $22(73)$ & $28(56)$ & $5(17)^{* * *}$ & $21(42)$ & $2(7)^{* * *}$ \\
\hline IBS-P \& HC-P $(n=50)$ & HC-N $(n=16)$ & $6(12)$ & $0(0)$ & $42(84)$ & $7(44)^{* * *}$ & $6(12)$ & $0(0)$ & $42(84)$ & $8(50)^{* *}$ & $45(90)$ & $13(81)$ & $39(78)$ & $9(56)$ & $28(56)$ & $2(13)^{* *}$ & $21(42)$ & $1(6)^{* *}$ \\
\hline IBS-P $(n=26)$ & IBS-N $(n=14)$ & $1(4)$ & $0(0)$ & $25(96)$ & $12(86)$ & $3(12)$ & $0(0)$ & $26(100)$ & $13(93)$ & $26(100)$ & $12(86)^{*}$ & $25(96)$ & $13(93)$ & $14(54)$ & $3(21)^{*}$ & $5(19)$ & $1(7)$ \\
\hline HC-P $(n=24)$ & HC-N $(n=16)$ & $5(21)$ & $0(0)^{\wedge}$ & $17(71)$ & $7(44)$ & $3(13)$ & $0(0)$ & $16(67)$ & $8(50)$ & $19(79)$ & $13(81)$ & $14(58)$ & $9(56)$ & $14(58)$ & $2(13)^{* *}$ & $16(67)$ & $1(6)^{* * *}$ \\
\hline \multicolumn{18}{|l|}{ GIT symptoms } \\
\hline IBS-P \& IBS-N $(n=40)$ & HC-P \& HC-N $(n=40)$ & $1[56]$ & $5(13)$ & $37(93)$ & $24(60)^{* * *}$ & $3(8)$ & $3(8)$ & $39(98)$ & $24(60)^{* * *}$ & $38(95)$ & $32(80)^{*}$ & $38(95)$ & $23(58)^{* * *}$ & $17(43)$ & $16(40)$ & $6(15)$ & $17(43)^{* *}$ \\
\hline IBS-P $(n=26)$ & HC-P \& HC-N $(n=40)$ & $1(4)$ & $5(13)$ & $25(96)$ & $24(60)^{* * *}$ & $3(12)$ & $3(8)$ & $26(100)$ & $24(60)^{* * *}$ & $26(100)$ & $32(80)^{*}$ & $25(96)$ & $23(58)^{* * *}$ & $14(54)$ & $16(40)$ & $5(19)$ & $17(43)^{*}$ \\
\hline IBS-P $(n=26)$ & $\mathrm{HC}-\mathrm{P}(n=24)$ & $1(4)$ & $5(21)$ & $25(96)$ & $17(71)^{*}$ & $3(12)$ & $3(13)$ & $26(100)$ & $16(67)^{* * *}$ & $26(100)$ & $19(80)^{*}$ & $25(96)$ & $14(58)^{* * *}$ & $14(54)$ & $14(58)$ & $5(19)$ & $16(67)^{* * *}$ \\
\hline IBS-P $(n=26)$ & HC-N $(n=16)$ & $1(4)$ & $0(0)$ & $25(96)$ & $7(44)^{* * *}$ & $3(12)$ & $0(0)$ & $26(100)$ & $8(50)^{* * *}$ & $26(100)$ & $13(81)^{*}$ & $25(96)$ & $9(56)^{* * *}$ & $14(54)$ & $2(13)^{* *}$ & $5(19)$ & $1(6)$ \\
\hline IBS-N $(n=14)$ & HC-P \& HC-N $(n=40)$ & $0(0)$ & $5(13)$ & $12(86)$ & $24(60)$ & $0(0)$ & $3(8)$ & $13(93)$ & $24(60)^{*}$ & $12(86)$ & $32(80)$ & $13(93)$ & $23(58)^{*}$ & $3(21)$ & $16(40)$ & $1(7)$ & $17(43)^{*}$ \\
\hline IBS-N $(n=14)$ & $\mathrm{HC}-\mathrm{N}(n=16)$ & $0(0)$ & $0(0)$ & $12(86)$ & $7(44)^{*}$ & $0(0)$ & $0(0)$ & $13(93)$ & $8(50)^{*}$ & $12(86)$ & $13(81)$ & $13(93)$ & $9(56)^{*}$ & $3(21)$ & $2(13)$ & $1(7)$ & $1(6)$ \\
\hline
\end{tabular}

Gp: group of study subjects; n: number of subjects; kDa: kiloDalton; MW: molecular weight

IBS-P/N: Irritable bowel syndrome subjects positive/negative for Blastocystis

HC-P/N: healthy control subjects positive/negative for Blastocystis

${ }^{*} p \leq 0.05 ;{ }^{* *} p \leq 0.01 ; * * * p \leq 0.001$ 


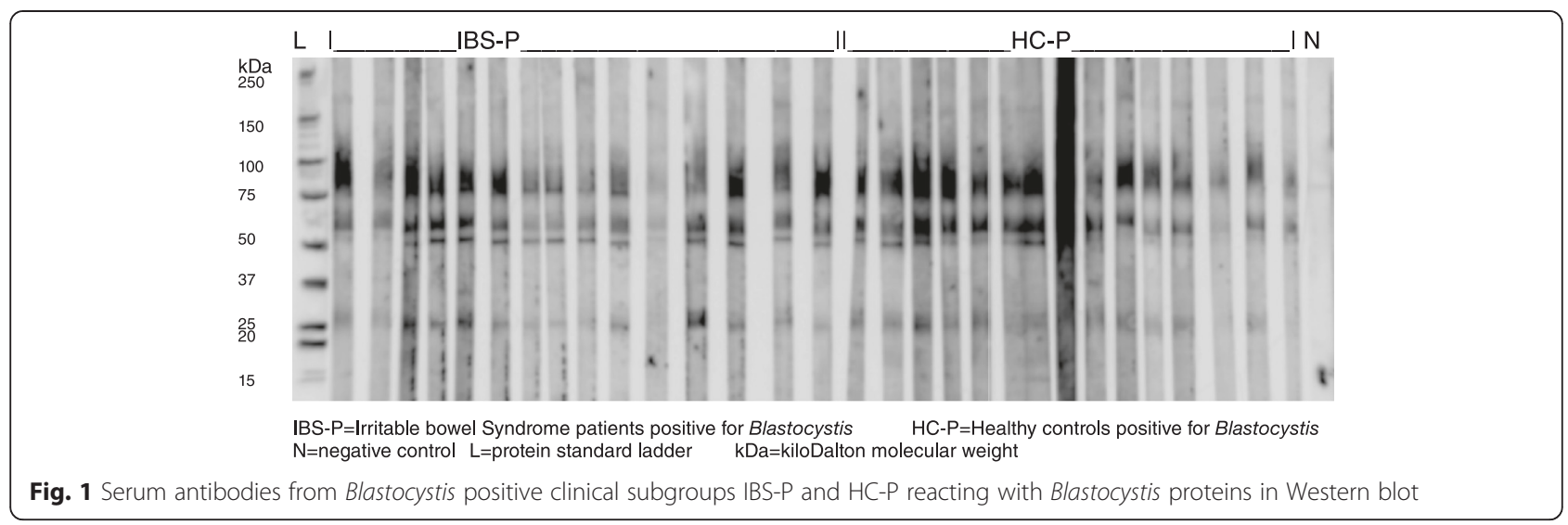

Reactivity with proteins of approximately 17 and $37 \mathrm{kDa} \mathrm{MW}$ were observed in $7.5 \%$ of total participants and these were only present in those subjects who tested positive for the presence of Blastocystis sp. Proportions of participants with reactivity for proteins of $95-105 \mathrm{kDa}$ and $150 \mathrm{kDa} \mathrm{MW}$, were significantly lower in the combined Blastocystis-negative group $\left(\lambda^{2}=11.97, p \leq 0.001\right.$ and $\lambda^{2}=11.43, p \leq 0.001$ respectively) (Table 3 ). The association of antibody-reactivity to the 95-105 kDa protein(s) with Blastocystis carriage was statistically significant in the intra-subgroup comparisons in both HC and IBS groups $(p \leq 0.05)$ (Table 4).

Reactivity to the 27, 50 and 75-90 kDa MW bands were detected in descending order of frequency in the
IBS-P group (96\%, $100 \%, 96 \%$ ), the IBS-N group (86 \%, $93 \%, 93 \%)$, the HC-P (71 \%, $67 \%, 58 \%)$ and the HC-N (44 \%, $50 \%, 56 \%$ ) groups (Table 3). Reactivity to each of these three proteins was found to be significantly associated with IBS symptoms, regardless of Blastocystis status (combined IBS-P + IBS-N $(p \leq 0.001)$, IBS-P $(p \leq 0.001)$ or IBS-N $(p<0.05)$, respectively, versus HC: Table 4).

\section{Further Analysis of the Blastocystis Antigens}

The Blastofluor ${ }^{\ominus}$ antibody was tested in parallel with IBS-P and HC-P sera on a Western blot and showed reactivity with all the protein bands noted in the

$\mathbf{2 5 0}$
$\mathbf{1 5 0}$
$\mathbf{1 0 0}$
$\mathbf{7 5}$
$\mathbf{5 0}$
IBS-P=Irritable Bowel Syndrome patient positive for Blastocystis HC-P=Healthy controls positive for Blastocystis
Western blot




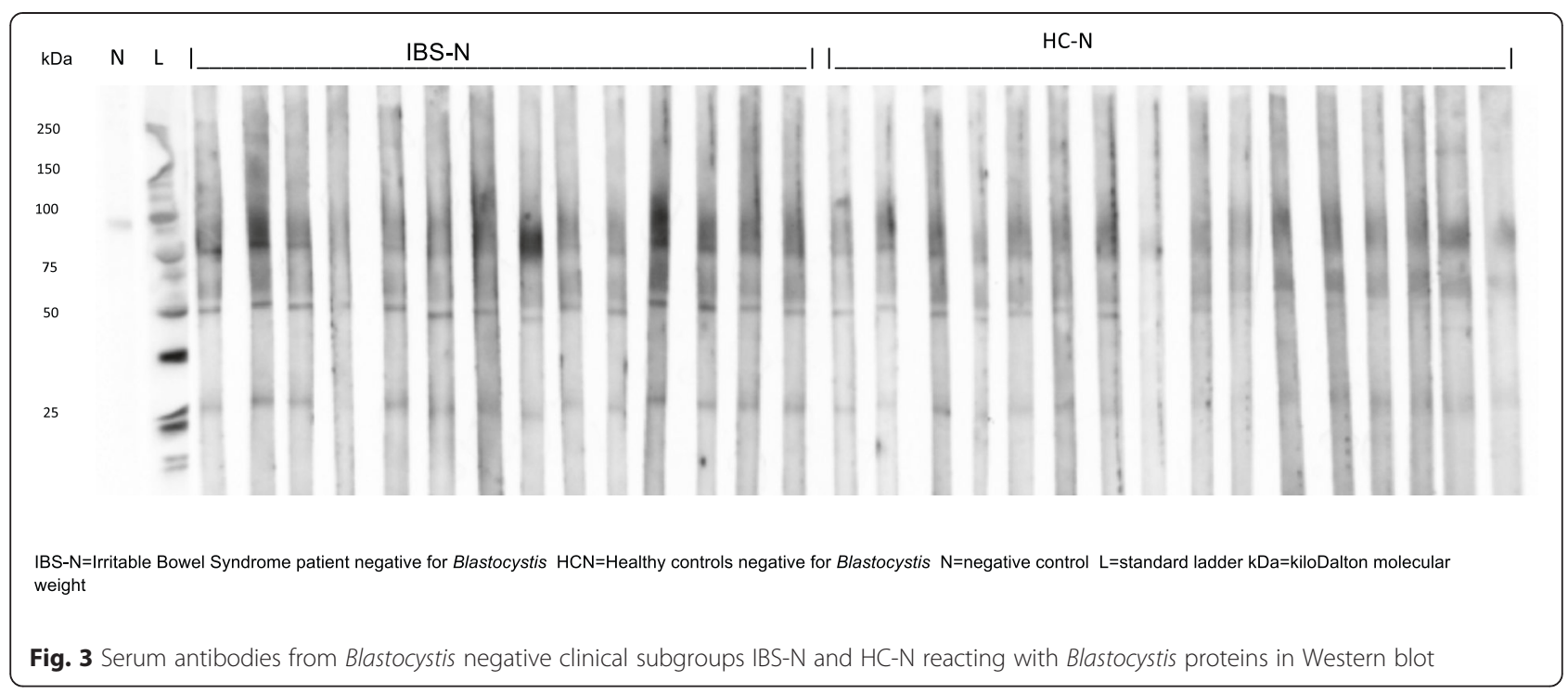

study subgroups, namely $17,27,37,50,60-65,75-$ 90, 95-105, 150 and $250 \mathrm{kDa}$ MW (Fig. 2).

The MAb1D5 and MAb5 monoclonal antibodies were tested in parallel with four sera derived from BSP patients on a Western blot. The MAb1D5 reacted strongly with two protein bands of approximately $100 \mathrm{kDa} \mathrm{MW}$ and less strongly with a27kDa protein. The MAb5 gaveno reactivity on the blot (Fig. 4). The anti-MMP-9 antibodies were tested in parallel with two BSP sera on a Western blot and the anti-MMP-9 antibodies reacted with proteins of 27, 50 and 75-100 kDa MW (Fig. 5).

The MAb1D5, MAb5, anti-MMP-9 were tested in parallel on a Western blot, using a $7.5 \%$ gel in an attempt to separate out the bands around 75-100 kDa MW, and this demonstrated that the MAb1D5 antibody reacted with a protein closer to $100 \mathrm{kDa} \mathrm{MW}$ compared to the anti-MMP-9 that reacted with a protein of approximately $80 \mathrm{kDa}$ (Additional file 1: Figure S1). Both antibodies reacted with a protein of approximately $25 \mathrm{kDa} \mathrm{MW}$.

A zymogram was run with and without EDTA (metalloprotease inhibitor). In the absence of EDTA two distinct bands above and below the $100 \mathrm{kDa}$ protein marker (approximately 95 and $105 \mathrm{kDa}$, respectively) were apparent. Addition of EDTA to the zymogram abolished these two bands (Additional file 2: Figure S2).

\section{Discussion}

Serum IgA levels were found to be significantly lower in subjects that were positive for Blastocystis sp. even after adjusting for the confounding variables of gender, age, season and Asian ethnicity that have been reported to influence serum IgA levels [35, 37]. The level of IgA correlated with carriage but not symptoms suggesting that a low serum IgA may permit Blastocystis sp. to establish in the gut lumen but may not influence pathogenicity. The association of Blastocystis carriage and low serum IgA would be consistent with the fact that IgA is the major immunoglobulin class involved in mucosal defence [38] and is known to prevent adherence of pathogens to the gut luminal surface, bind toxins and inhibit antigen absorption. IgA production increases after three months of age in parallel with the change from a sterile gut to one with a complex commensal intestinal microbiota [39]. Secretory IgA can be effective against pathogens as an innate non-specific local response or develop into an adaptive specific systemic response after presentation of luminal antigen to gut associated lymphoid tissue (GALT) and subsequent generation of IgA-producing plasma cells in the intestinal mucosa. The complex relationship of IgA to the regulation or monitoring of the intestinal microbiota is not understood. Proteases derived from Blastocystis cell lysates have been shown to be capable of degrading secretory IgA [28].

Low serum levels of IgA may be due to a number of causes including partial or complete selective IgA deficiency [40] and likely influence host and microbial interactions. IgA deficiency is associated with an increased risk of giardiasis (caused by another non-invasive luminal parasite) as well as respiratory infections and allergic and autoimmune diseases [38]. Patients with autoimmune diseases and selective IgA deficiency more commonly exhibit the major histocompatibility complex (MHC) haplotype 8.1 and other non-MHC gene defects have been reported [41].

IgG serum antibodies from many study participants in all subgroups reacted with proteins of approximately 27 , $50,60-65,75-90,95-105$, and $150 \mathrm{kDa} \mathrm{MW}$ in the 

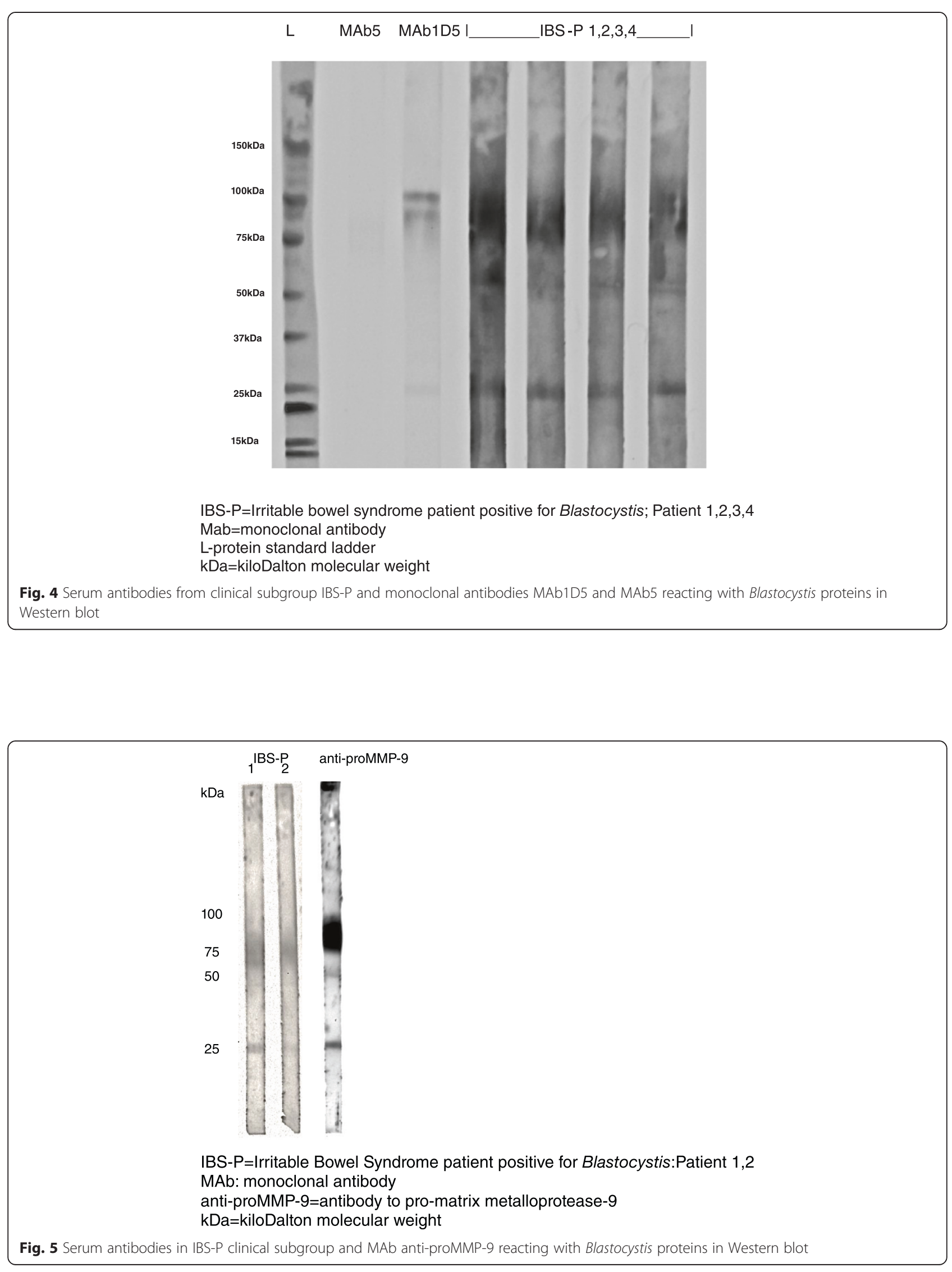
Western blots using axenic WR1 (ST4) as antigen source. Although differences in the quantity or affinity of the antibodies were suggested by the intensity of the signals, no attempt was made to apply quantitation by densitometry. The rabbit-derived Blastofluor ${ }^{\circ}$ antibody, raised in rabbits primed with axenic ST3, showed a very similar reactivity pattern to proteins of $10,17,27,37,50$, 75, $100 \mathrm{KDa} \mathrm{MW}$ when tested in parallel with human sera (Fig. 2), suggesting that these particular Blastocystis antigens are common to both subtypes 3 and 4. Whilst some researchers have described different SDS-PAGE protein patterns in different Blastocystis organisms [42, 43] others have found little difference in the protein sizes between different Blastocystis subtypes [31, 44].

Over $40 \%$ of healthy asymptomatic patients negative for Blastocystis sp. reacted to Blastocystis antigens at 27, $50,60-65$ and 75-90 kDa, respectively (Table 3), suggesting that positive reactions with these proteins occurred either due to past exposure to Blastocystis sp. or as a result of a cross reactivity with the Blastocystis antigens. Only the antibody band sizes 95-105 and 150kDA were significantly more common in those with current carriage of Blastocystis sp., occurring in approximately $60 \%$ of these individuals.

However, IBS groups, either positive or negative for Blastocystis carriage, when compared to $\mathrm{HC}$ displayed a different pattern with significantly higher number of reactions to 27, 50 and $75-95 \mathrm{kDaMW}$ proteins. Overall these proteins were present in approximately 86-100\% of IBS patients compared to $44-71 \%$ of HC. Although presence of these proteins was greatest in the Blastocystis-positive IBS group, it was still present in the IBS group negative for current carriage of Blastocystis sp.. This finding again suggests the positive reactions in the IBS-N group were either due to non-specific antibody cross-reactions or due to residual antibody from past exposure to Blastocystis organisms. The gut epithelial permeability is increased in IBS $[7,45]$ and it is probable that IBS patients have greater exposure to intraluminal antigens. Although the number of subjects in our clinical subgroups was relatively small our findings suggest that exploration of the nature of these 27, 50, 75-95 kDa MW proteins may be useful in identifying biomarkers for IBS (current biomarkers are not able to reliably exclude organic disease [4]), identifying patients who are symptomatic due to Blastocystis infection and informing development of effective therapies.

Several studies have reported that an antigenic protein with a MW of approximately $30 \mathrm{kDa}$ is present in Blastocystis organisms $[17,46]$ and differences in reactivity to this protein(s) between symptomatic patients and healthy controls have been reported [17, 47]. No reactivity with proteins of this size was reported in sera from patients with other parasitic infections suggesting the $30 \mathrm{kDa}$ protein might be specific for Blastocystis organisms. A cytopathic monoclonal antibody, MAb1D5, previously shown to bind to the external surface of Blastocystis sp. [32], reacts with a30kDa protein from Blastocystis isolates derived from humans (ST's unknown), but reportedly not with antigen derived from WR1 [24]. Peptide sequences derived from material obtained by 2-dimensional electrophoresis and Western blotting suggest that this $30 \mathrm{kDa}$ protein is closely related to a cysteine protease of the legumain type. Although no reactivity of the MAb1D5 was reported previously with subtype WR1 [24], and this was the subtype we used as an antigen source in our study, the $27 \mathrm{kDa}$ protein-reactivity that we observed more frequently in the symptomatic group may nevertheless correspond to this previously described $30 \mathrm{kDa}$ protein. The difference in reactivity may be accounted for by increased purity of MAb1D5 used in our study and differences in antigen preparation technique, and the MW size difference accounted for by differences in Blastocystis antigen source and preparation (e.g., subtype, level of glycosylation). The MAb1D5 tested in parallel with our human serum samples reacted strongly with a double band around $100 \mathrm{kDa} \mathrm{MW}$ and also with a $27 \mathrm{kDa}$ protein in the Western blots (Fig. 4). This pattern of reactivity (100 and $\sim 30 \mathrm{kDa}$ ) against an antigen preparation using ST7 organisms was shown previously [27] and suggests that the $30 \mathrm{kDa}$ antigen may be a processed or degraded form of the $100 \mathrm{kDa}$ protein.

We also noted differences in IBS patients (IBS-P and IBS-N) with regard to reactivity to 50 and 75$95 \mathrm{kDa}$ proteins. These proteins may correspond to the 50 and $118 \mathrm{kDa}$ antigens [17], or the $60-100 \mathrm{kDa}$ sized proteases [48] reported previously in symptomatic Blastocystis infected patients. Parasitic proteases are known to be highly immunogenic and may facilitate tissue invasion in the host. We searched for a protease that might be consistent with this role and sizes. Matrix metalloproteinase-9 (MMP-9) is one member of the zinc binding matrix metalloproteinases (MMP) that degrade components of the extracellular matrix including gelatin (gelatinase B), collagens, and elastin, thereby potentially aiding tissue invasion [49], and has been shown to interact with the immune system including potentiation of IL-8 [49]. MMP-9's are found in the cytosol, vesicles and cell membranes of cells [50]. They exist as a pro-enzyme at around $92 \mathrm{kDa}$, an activated form around $84 \mathrm{kDa}$ and truncated forms at lower sizes around $50 \mathrm{kDa}$ in humans [51]. The pro-MMP-9's are activated by other proteases, detergents and heat. We tested an antibody specific for human pro-MMP-9 in parallel with human sera in our Western blots and found that it reacted with Blastocystis proteins of approximately 75-100, 
50 and $27 \mathrm{kDa} \mathrm{MW}$, respectively, and that the pattern differed from the MAb1D5 reactivity. MAb1D5 reacted with a different distinct protein of approximately $95 \mathrm{kDa}$ as well as a27kDa protein.

A subsequent zymogram performed using antigen that had been pre-treated with protease inhibitors minus EDTA showed a positive double band around $100 \mathrm{kDa}$ that was abolished with EDTA. These findings suggest that a metalloproteinase around $100 \mathrm{kDa} \mathrm{MW}$ is present in Blastocystis sp.. Inherent differences in gel runs and species variation of enzymes make it difficult to assess if this $100 \mathrm{kDa}$ zymogram band is related to the Western blot 75-95 kDa bands we noted to be of significance in symptomatic patients. The findings nevertheless suggest that a MMP-9 isoform is present in Blastocystis organisms, and the pro-MMP-9 band may correspond to the 75-95 $\mathrm{kDa}$ protein, while the $50 \mathrm{kDa}$ protein may possibly be the enzymatically active form and the $27 \mathrm{kDa}$ form a truncated fragment.

The detection of a $27 \mathrm{kDa}$ protein with both the antiMMP-9 and the MAb1D5 suggest that this band may contain more than one protein, including a truncated fragment of a MMP-9 isoform. Previous studies investigating proteases present in Blastocystis sp. have suggested that cysteine proteases constitute the major class of proteases in this organism $(80 \%$ protease activity shown to be inhibited by cysteine protease inhibitors) [52]. However it may be difficult to account for proteases that are present as pro-enzymes that require activation or that may be inhibited from converting to active forms by other proteases. Protease activity at $32 \mathrm{kDa}$ was reported to be significantly increased in symptomatic patients $[47,53]$ but may be due to a mixture of enzymes of that size. The genome of ST7 has been sequenced and this has allowed the prediction that all classes of proteases (cysteine, serine and metalloproteases) could be secreted by the parasite [26]. The majority (91\%) are predicted to be of the cysteine protease and none were specifically predicted, at this level of genome testing sensitivity, to be a metalloprotease of the MMP-9 class. Preliminary analysis of the ST4 genome has shown the presence of up to $30 \%$ genes with no ortholog present in the ST7 genome [54] emphasising the genetic diversity present in this organism. Additionally, a recent study has discovered that $15 \%$ of nuclear genes in Blastocystis sp. Subtype 7 uniquely use a polyadenylationmediated creation of termination codons [55] and predicted genes may need to be re-evaluated in the light of this new information.

\section{Conclusions}

Low serum IgA levels may facilitate Blastocystis carriage but are not associated with the development of IBS gastrointestinal symptoms. Antibodies to Blastocystis organisms are commonly found in the serum of many healthy individuals, but antibodies to 27, 50 and 75$95 \mathrm{kDa} \mathrm{MW}$ proteins are significantly increased in IBS patients regardless of Blastocystis status. Some of these serum antibodies are likely to be reacting to a previously reported cysteine protease, but others may be reacting with another class of proteases, the metalloproteases.

\section{Additional files}

Additional file 1: Figure $\mathbf{S 1}$. Anti-proMMP-9, MAb1D5, MAb5 reacting with Blastocystis proteins in a Western blot. (PDF $292 \mathrm{~kb}$ )

Additional file 2: Figure S2. Zymogram of Blastocystis WR1 proteins without addition of EDTA. (PDF $70 \mathrm{~kb}$ )

\section{Abbreviations}

DNA: Deoxyribonucleic acid; EDTA: Ethylenediaminetetraacetic acid; GALT: Gut associated lymphoid tissue; HC: Healthy controls; HC-N: Healthy controls negative for Blastocystis spp.; HC-P: Healthy controls positive for Blastocystis spp.; IBS: Irritable bowel syndrome; IBS-N: Patients with irritable bowel syndrome negative for Blastocystis spp.; IBS-P: Patients with irritable bowel syndrome positive for Blastocystis spp.; IgA: Immunoglobulin A; IgG: Immunoglobulin G; IgM: Immunoglobulin M; IMDM: Iscove's modified Dulbecco's medium; kDa: kiloDalton; MAb: Monoclonal antibody; MMP: Promatrix metallopotease-9; MW: Molecular weight; PBS: Phosphate buffered saline; PBS/T: Phosphate buffered solution/Tween 20; PCR: Polymerase chain reaction; SDS-PAGE: Sodium dodecyl sulphate polyacrylamide gel electrophoresis; ST: Subtype; S: Subunit; Sp.: Species; rDNA: Gene coding for ribosomal ribonucleic acid; XIVC: Xenic in vitro culture.

\section{Competing interests}

The authors declare that they have no competing interests.

\section{Authors' contributions}

RAN: Development of study outline, acquisition of specimens, laboratory analysis of specimens, discussion of results, writing of paper (55\%). RJT: Development study outline, discussion of results, editing of paper (15\%). MMSK: Discussion of results, statistical analysis, editing of paper (10\%). HBO: Development of study outline, laboratory analysis, discussion of results, editing of paper (20\%). All authors read and approved the final version of the manuscript.

\section{Acknowledgments}

We are grateful for the kind donations of important research material by Dr Linda Dunn, QIMR, Australia (axenic cultures of Blastocystis for antigen preparation), Dr Rick Gould, Antibodies Inc, USA (Blastofluor ${ }^{\oplus}$ antibody) and Dr Kevin Tan, NUS, Singapore (MAb 1D5, MAb5), who also read the manuscript and contributed useful comments. This study was funded by the Royal Australian College of Physicians Murray-Will Fellowship for Rural Physicians (awarded to R. Nagel, 2012).

\section{Author details}

${ }^{1}$ School of Veterinary Science, The University of Queensland, Gatton Campus, Gatton, QLD 4343, Australia. ${ }^{2}$ Faculty of Veterinary and Agricultural Sciences, University of Melbourne, Parkville, VIC 3052, Australia. ${ }^{3}$ Rural Clinical School, School of Medicine, The University of Queensland, Toowoomba 4350, Australia. ${ }^{4}$ Australian Infectious Diseases Research Centre, The University of Queensland, St. Lucia, QLD 4072, Australia. ${ }^{5}$ Toowoomba Gastroenterology Clinic, Suite 105 Medici Medical Centre, 15 Scott St, Toowoomba, QLD 4350, Australia.

Received: 5 May 2015 Accepted: 3 September 2015

Published online: 15 September 2015 


\section{References}

1. Canavan C, West J, Card T. The epidemiology of irritable bowel syndrome. J Clin Epidemiol. 2014;6:71-80.

2. Whorwell PJ. IBS in 2014: Developments in pathophysiology, diagnosis and management. Nat Rev Gastroenterol Hepatol. 2015;12(2):72-4

3. Longstreth GF, Thompson WG, Chey WD, Houghton LA, Mearin F, Spiller RC. Functional Bowel Disorders. Gastroenterology. 2006;130(5):1480-91.

4. Corsetti M, Van Oudenhove L, Tack J. The quest for biomarkers in IBS-where should it lead us? Neurogastroenterol Motil. 2014;26(12):1669-76.

5. Lembo AJ, Neri B, Tolley J, Barken D, Carroll S, Pan H. Use of serum biomarkers in a diagnostic test for irritable bowel syndrome. Aliment Pharmacol Ther. 2009;29(8):834-42.

6. Jones MP, Chey WD, Singh S, Gong H, Shringarpure R, Hoe N, et al. A biomarker panel and psychological morbidity differentiates the irritable bowel syndrome from health and provides novel pathophysiological leads. Aliment Pharmacol Ther. 2014;39(4):426-37.

7. Beatty JK, Bhargava A, Buret AG. Post-infectious irritable bowel syndrome: Mechanistic insights into chronic disturbances following enteric infection. World J Gastroenterol. 2014;20(14):3976-85.

8. Yakoob J, Jafri W, Beg MA, Abbas Z, Naz S, Islam M, et al. Irritable bowel syndrome: is it associated with genotypes of Blastocystis hominis. Parasito Res. 2010;106(5):1033-8.

9. Tan KSW. New insights on classification, identification, and clinical relevance of Blastocystis spp. Clin Microbiol Rev. 2008;21(4):639-65.

10. Stensvold CR. Comparison of Sequencing (Barcode Region) and SequenceTagged-Site PCR for Blastocystis Subtyping. J Clin Microbiol. 2013;51:190-4.

11. Stensvold CR. Blastocystis: genetic diversity and molecular methods for diagnosis and epidemiology. Trop Parasitol. 2015;3(1):26-34.

12. Poirier P, Wawrzyniak I, Vivares CP, Delbac F, El Alaoui H. New insights into Blastocystis species; a potential link with irritable bowel syndrome. PLoS Pathog. 2012;8(3), e1002545.

13. Phillips BP, Zierdt $\mathrm{CH}$. Blastocystis hominis: pathogenic potential in human patients and in gnotobiotes. Exp Parasitol. 1976;39(3):358-64.

14. Wang W, Bielefeldt-Ohmann H, Traub RJ, Cuttell L, Owen H. Location and pathogenic potential of Blastocystis in the porcine intestine. PLoS One. 2014:5(9 (8)):e103962.

15. Zierdt $\mathrm{CH}$, Nagy B. Antibody response to Blastocystis hominis infections. Ann Intern Med. 1993;118(12):985-6.

16. Kaneda Y, Horiki N, Cheng X, Tachibana H, Tsutsumi Y. Serologic response to Blastocystis hominis infection in asymptomatic individuals. Tokai J Exp Clin Med. 2000;25(2):51-6.

17. Hegazy MM, Maklouf LM, El Hamshary EM, Dawoud HA, Eida AM. Protein profile and morphometry of cultured human Blastocystis hominis from children with gastroenteritis and healthy ones. J Egypt Soc Parasitol. 2008;38(2):453-64.

18. Gamra MM, Elwakil HS, El Deeb HK, Khalifa KE, Elhafiz HE. The potential use of $29 \mathrm{kDa}$ protein as a marker of pathogenicity and diagnosis of symptomatic infections with Blastocystis hominis. Parasitol Res. 2011;108:1139-46.

19. Wang W, Cuttell L, Traub RJ, Owen H, Bielefeldt-Ohmann H. Characterisation of the Blastocystis specific faecal IgA immune response in pigs. Parasite Immunol. 2014;9(8):e:103962.

20. Mahmoud MS, Saleh WA. Secretory and humoral antibody responses to Blastocystis hominis in symptomatic and asymptomatic human infections. J Egypt Soc Parasitol. 2003;33(1):13-30.

21. Nagel R B-OH, Traub R. Clinical pilot study: Efficacy of triple antibiotic therapy in Blastocystis positive Irritable Bowel Syndrome patients. Gut Pathogens. 2014;6(34):1-9.

22. Garavelli PL, Zierdt CH, Fleisher TA, Liss H, Nagy B. Serum antibody detected by fluorescent antibody test in patients with symptomatic Blastocystis hominis infection. Recenti Prog Med. 1995;86(10):398-400.

23. Wu B, Yin J, Texier C, Roussel M, Tan KS. Blastocystis legumain is localized on the cell surface, and specific inhibition of its activity implicates a pro-survival role for the enzyme. J Biol Chem. 2010;285(3):1790-8.

24. Tan KS, Ibrahim M, Ng GC, Nasirudeen AMA, Ho LC, Yap EH, et al. Exposure of Blastocystis species to a cytotoxic monoclonal antibody. Parasitol Res. 2001;87(7):534-8.

25. McKerrow JH. Parasite proteases. Exp Parasitol. 1989:68:111-5.

26. Denoeud F, Roussel M, Noel B, Wawrzyniak I, Da Silva C, Diogon M, et al. Genome sequence of the stramenopile Blastocystis, a human anaerobic parasite. Genome Biol. 2011;12(3):R29.
27. Wawrzyniak I, Texier C, Poirier P, Viscogliosi E, Tan KSW, Delbac F, et al. Characterization of two cysteine proteases secreted by Blastocystis ST7, a human intestinal parasite. Parasitol Int. 2012;61(3):437-42.

28. Puthia MK, Vaithilingam A, Lu J, Tan KSW. Degradation of human secretory immunoglobulin A by Blastocystis. Parasitol Res. 2005;97(5):386-9.

29. Puthia MK, Sio SWS, Lu J, Tan KSW. Blastocystis ratti Induces Contact Independent Apoptosis, F-Actin Rearrangement, and Barrier Function Disruption in IEC-6 Cells. Infect Immun. 2006:74(7):4114-23.

30. Drossman DA. Introduction. The Rome Foundation and Rome III. Neurogastroenterol Motil. 2007:19(10):783-6.

31. Tan SW, Ho LC, Moe KT, Chen XQ, Ng GC, Yap EH, et al. Production and characterization of murine monoclonal antibodies to Blastocystis hominis. Int J Parasitol. 1996;26(4):375-81.

32. Tan SW, Singh M, Ho LC, Howe J, Moe KT, Chen XQ, et al. Survival of Blastocystis hominis clones after exposure to a cytotoxic monoclonal antibody. Int J Parasitol. 1997;27(8):947-54

33. Gould R, Boorom K. Blastocystis surface antigen is stable in chemically preserved stool samples for at least 1 year. Parasitol Res. 2013;112:2469-71.

34. IBM SPPS S. IBM SPPS Statistics for Windows, Version 22.0. 2013.

35. Weber-Mzell D, Kotanko P, Hauer AC, Goriup U, Haas J, Lanner N, et al. Gender, age and seasonal effects on IgA deficiency, a study of 7293 Caucasians. Eur J Clin Investigation. 2004;34:224-8.

36. Yakoob J, Abbas Z, Usman MW, Sultana A, Islam M, Awan S, et al. Cytokine changes in colonic mucosa associated with Blastocystis spp. subtypes 1 and 3 in diarrhea-predominant irritable bowel syndrome. Parasitology. 2014;141:957-67.

37. Stoop JW, Zegers BJ, Sanders PC, Ballieux RE. Serum immunoglobulin levels in helathy children and adults. Clin Exp Immunol. 1969;4:101-12.

38. Aghamohammadi A, Cheraghi T, Gharagozlou M, Movahedi M, Rezaei N, Yeganeh $\mathrm{M}$, et al. IgA deficiency: Correlation between Clinical and Immunologic Phenotypes. J Clin Immunol. 2009;29:130-6.

39. Macpherson AJ, McCoy KD, Johansen FE, Brandtzaeg P. The immune geography of $\lg A$ induction and function. Mucosal Immunol. 2008;1(1):11-22.

40. Latiff AHA, Kerr MA. The clinical significance of immunoglobulin A deficiency. Ann Clin Biochem. 2007:44:131-9.

41. Singh K, Chang C, Gershwin ME. IgA deficiency and autoimmunity. Autoimmun Rev. 2014;13(2):163-77.

42. Kukoschke K, Muller H. SDS-PAGE and immunological analysis of different axenic Blastocystis hominis strains. J Med Microbiol. 1991;35:35-9.

43. Chen $X Q$, Singh M, Ho LC, Tan SW, Yap EH. Characterization of protein profiles and cross-reactivity of Blastocystis antigens by sodium dodecyl sulfate-polyacrylamide gel electrophoresis and immunoblot analysis. Parasitol Res. 1999;85(4):343-6.

44. Init I, Mak JW, Top S, Zulhainan Z, Prummongkol S, Nissapatorn V, et al. Polypeptides associated with in vitro cyst formation of Blastocystis hominis. Southeast Asian J Trop Med Public Health. 2003;34(4):727-32.

45. Simren M, Barbara G, Flint HJ, Spiegel BM, Spiller RC, Vanner S, et al. Intestinal microbiota in functional bowel disorders: a Rome foundation report. Gut. 2013:62(1):159-76.

46. Lanuza MD, Carbajal JA, Villar J, Mir A, Borras R. Solube-protein and antigenic heterogeneity in axenic Blastocystis hominins isolates: pathogenic implications. Parasitol Res. 1999;85:93-7.

47. Abou Gamra MM, Elwakil HS, El Deeb HK, Khalifa KE, Abd Elhafiz HE. The potential use of $29 \mathrm{kDa}$ protein as a marker of pathogenicity and diagnosis of symptomatic infections with Blastocystis hominis. Parasitol Res. 2011;108(5):1139-46

48. Rajamanikam A, Govind SK. Amoebic forms of Blastocystis spp.-evidence for a pathogenic role. Parasites and Vectors. 2013;6:295.

49. Geurts N, Opdenakker G, Van den Steen PE. Matrix metalloproteinases as therapeutic targets in protozoan parasitic infections. Pharmacol Ther 2012;133(3):257-79.

50. Vandooren J, Van den Steen PE, Opdenakker G. Biochemistry and molecular biology of gelatinase $B$ or matrix metalloproteinase-9 (MMP-9): the next decade. Crit Rev Biochem Mol Biol. 2013:48(3):222-72.

51. Shimokawa K, Katayama M, Matsuda Y, Takahashi H, Hara I, Sato H, et al. Matric metalloproeteinase (MMP)-2 and MMP-9 activities in human seminal plasma. Mol Hum Reprod. 2002;8(1):32-6.

52. Sio SWS, Puthia MK, Lee AS, Lu J, Tan KS. Protease activity of Blastocystis hominis. Parasitol Res. 2006;99(2):126-30. 
53. Abdel-Hameed DM, Hassanin OM. Proteaese activity of Blastocystis hominis subtype3 in symptomatic and asymptomatic patients. Parasitol Res. 2011:doi:10.1007/s00436-00011-02259-x.

54. Wawryniak I, Courtine D, Osman M, Hubans-Pierlot C, Cian A, Nourrisson C, et al. Draft genome sequence of the intestinal parasite Blastocystis subtype 4-isolate WR1. Genomics Data. 2015;4:22-3.

55. Klimes V, Gentekaki E, Roger AJ, Elias M. A large number of nuclear genes in the human parasite blastocystis require mRNA polyadenylation to create functional termination codons. Genome Biol Evol. 2014;6(8):1956-61.

56. Bailar 3rd JC, Mosteller F. Guidelines for statistical reporting in articles for medical journals. Amplifications and explanations. Ann Intern Med. 1988;108(2):266-73.

\section{Submit your next manuscript to BioMed Central and take full advantage of:}

- Convenient online submission

- Thorough peer review

- No space constraints or color figure charges

- Immediate publication on acceptance

- Inclusion in PubMed, CAS, Scopus and Google Scholar

- Research which is freely available for redistribution 